\title{
Human Rights-based Approach to Maternal Health Policy and Implementation: An Analysis of Abiye Safe-Motherhood Policy of Ondo State Nigeria
}

\author{
Kikelomo Aboyowa Mbada \\ Department of Political Science, Faculty of Social Sciences \\ Obafemi Awolowo University, Ile-Ife, Nigeria
}

Received: Dec. 13, 2020 Accepted: Jan. 12, 2021 Online published: Jan. 20, 2021

doi:10.5296/jpag.v10i4.18218～URL: https://doi.org/10.5296/jpag.v10i4.18218

\begin{abstract}
A human rights-based approach that recognizes that women deserve the right to health is critical to achieving equitable reduction of maternal mortality in Nigeria, a country that is the second largest contributor to global maternal mortality. This study evaluated the extent to which the Abiye safe motherhood policy of the Ondo State government of Nigeria incorporated human rights-principles in its formulation and implementation. The study involved interviews and focus group discussions and the OHCHR human rights principles served as the basis for the thematic analysis of data. Findings indicate that the Abiye initiative exemplified the core principles of human rights-based approach to maternal health. Whereas, the initiative showed stronger practice in terms of the principles of participation, empowerment, non-discrimination and international assistance, there was limited indication of adherence to accountability, transparency, and sustainability principles. The Abiye safe motherhood initiative responded to maternal health needs in fairly acceptable and equitable ways; allowing the creation of opportunities and enabling conditions for the fulfillment of the health rights of reproductive-age women. It is recommended that governments at all levels should prioritize incorporating human rights-based standards into new or existing programs in a way that meets the core needs of respect and welfare of every woman in pregnancy and childbirth.
\end{abstract}

Keywords: maternal health, Abiye, safe motherhood, policy, human rights, Ondo State

\section{Introduction}

Despite the fact that women died from pregnancy and childbirth complications than from any other cause, maternal mortality remained a 'neglected tragedy' until 1985 when it began to gain attention in policy-making and research (Rosenfield and Maine, 1985). Maternal 
mortality was recognized as a public and global health problem in the development community in 1987 (Starrs in Storeng, 2010 p.79) and subsequently, it has been discussed at international conferences on women's health. Furthermore, a number of safe motherhood programmes implemented by governments and donor organizations and global efforts such as observed in the Sustainable Development Goals (SDG 3.1) have gone into addressing maternal mortality (Stanton, Kwast, Shaver, McCallon, \& Koblinsky, 2018).

As part of efforts to address the maternal mortality crisis in Nigeria, both national and subnational governments have enacted maternal health-related policies and programmes however, a number of these have been considered short of global best practices (Bankole, Sedgh, Okonofua, Imarhiagbe, Hussain, Wulf, 2009). Besides, political priority for maternal health is low both at the national and subnational levels (Shiffan \& Okonfua, 2007). Budgetary allocation to the health sector has averaged $6 \%$ in the last 15 years as against the recommended $15 \%$ of annual total budget in the 2001 Abuja Declaration (Izugbara, Wekessah, and Adedini, 2016). Similarly, annual per capita spending on health is currently at an average of US\$1, a far cry from the international recommendation of US\$34 (FMOH, 2014).

Predictably, maternal mortality in Nigeria remains unacceptably high at a ratio of 917 deaths per 100,000 live births and 60,000 maternal deaths occurring annually, most of which are preventable (WHO, 2019). This indisputably makes maternal mortality a human rights issue in Nigeria (Olonade, Olawande, Alabi, \& Imhonopi 2019; Piane, 2019). The preamble of the 1946 Constitution of the WHO states that "the enjoyment of the highest attainable standard of health is one of the fundamental rights of every human being...." and this includes the right to medical care (Rudan 2010; Hunt and Bueno De Mesquita 2007). Key aspects of the right to health are presented in the WHO (2013) document which clarifies that the 'right to health' does not mean the 'right to be healthy' but the "right to the enjoyment of a variety of goods, facilities, services and conditions necessary for the realization of health" (WHO, 2013).

Governments are aware of citizens' right to health and have an obligation to cater for the health of its citizens although they may be constrained in what extent they can do so due to resource constraints. They ought to put in efforts to guarantee a "minimum level of access to the essential material components of the right to health such as the provision of essential drugs and maternal and child health services" (WHO, 2013). This is particularly crucial for populations which have greater vulnerability and a higher predilection to health problems and as a result, need timely, acceptable and affordable health care (WHO, 2013). The significant regional and state-level differences in maternal health outcomes in Nigeria highlight the need for well-targeted local initiatives to address maternal health challenges in the country. However, only a few state governments in the country are confronting maternal deaths in an aggressive, deliberate and comprehensive manner (Cooke and Tahir, (2013).

Simply identifying relevant interventions and implementing policies are not enough to achieve equitable reduction of maternal mortality; a human rights-based approach that recognizes that women deserve a right to health is critical (Strauss \& Ward, 2013; Abegaz, 2019). This will require that the structural discrimination women face in health systems is challenged in a way that opens opportunities for women to claim their rights and benefit from conditions necessary 
for the realization of their health (Yamin, 2008b; 2013a). The Abiye Initiative is a sub-national home-grown safe motherhood policy of the Ondo State Government in Nigeria. This study evaluates the formulation and implementation of Abiye based on the Office of the United Nations High Commissioner for Human Rights (OHCHR) human rights principles for understanding maternal mortality and morbidity as a human rights issue. The principles comprise accountability, participation, transparency, empowerment, sustainability, international assistance and non-discrimination.

\section{Method}

A qualitative study based on interviews and focus group discussions was carried out. In order to obtain comprehensive understanding of the subject matter, providers, users and policy makers were interviewed on the extent to which the Abiye safe motherhood policy of Ondo State incorporated human rights-principles in its formulation and implementation to meet the core needs of women of reproductive-age in relation to maternal health. OHCHR principles for understanding maternal mortality and morbidity as a human rights issue was used as a guide (OHCHR, 2020).

Ondo state was purposively selected for this study as it represents the state with the highest positive changes in three maternal health indicators: antenatal care visits, institutional delivery and skilled attendant at birth (NPC and ICF Macro, 2009; NPC and ICF International, 2014). These indicators mentioned above are commonly used in maternal health studies to measure performance (Carpenito-Moyet, 2008:810, Grundy and Annear 2010:1-2; Bayou, 2014). Moreover, Ondo State is one of the few states to have exemplified significantly improved maternal mortality rate in a short time span to a greater extent than did any other state in the Southwestern region. Abiye Safe-Motherhood initiative of the Ondo State government has been acclaimed nationally and internationally as one of the best home-grown efforts running on strong political will and commitment, for the reduction of maternal mortality in Nigeria (Cooke and Tahir, 2013; Ondo State Ministry of Health, 2017). The initiative was designed to counter delay in health seeking, delay in reaching care, delay in accessing care and delay in referring care (the four major delays that precipitate and perpetuate maternal deaths in the State) (Ondo State Ministry of Health, 2017).

The study population was spread among four stakeholder groups centrally involved in maternal health policy formulation and policy implementation: government officials, the academia, maternal health service providers and users. The first group consisted of the Executive Governor, Permanent Secretaries and Directors in Ministries of Health. The second group consisted of maternal health experts working in medical colleges and research institutions with significant influence on policy decisions in the selected States. The third group comprised Medical Directors and Heads of Nursing Departments in the selected secondary health facilities; and the fourth group, comprised reproductive age women who have children aged less than five years and have accessed maternal health services in the selected health facilities.

There is no rule as to the required sample size for interviews in qualitative studies, however, between twelve and sixty interviews have been recommended to meet rigour and 
trustworthiness requirements (ten Have, 2004; Silverman, 2006). In this study, interviews were conducted with a purposively selected sample of 15 respondents saddled with maternal health policy and implementation responsibilities. In addition, focus group discussions were conducted (two in each of the six health facilities visited) among women who had accessed maternal health care services in selected secondary health facilities in Ondo state.

Participants were properly briefed about the purpose of the study and their consents were gained. While all interviews were conducted in English, a greater number of the FGDs were done in Yoruba language (Yoruba, a language spoken by the ethnic Yoruba people is the native dialect in the setting where this study was conducted). The interviews and FGDs (involved 8-10 participants per group) lasted for about 30 minutes and more each, and were audio recorded with the permission of the participants.

Ethical approval for the main study was sought from the Ethical Review Committee of the Institute of Public Health (IPH) (IPHOAU/12/824) of the Obafemi Awolowo University (OAU), Ile-Ife, Nigeria, and the Ethics and Review Committee of the Hospital Management Board, Ondo State (Refs AD.4693 Vol. II/110 and G.8061/117). Respondents were duly informed about the purpose of the study, their rights to participate or not, and assured protection of their identities in data storage and reporting were emphasized. Thereafter, signed informed consent indicating respondents' willingness to participate in the study, was gained. Additionally, permissions were sought to tape record interviews and FGDs.

Data Analysis

Recordings of interviews and FGDs were transcribed verbatim and recordings in Yoruba language were translated to English. Identities in transcripts were coded to ensure anonymity. ATLAS.ti, a qualitative data analysis and research software was used to carry out data coding and categorizing. The codes (supported by literature) were sorted into themes which were discussed in line with the objectives of the study.

\section{Results and Discussions}

While all levels of government have legal obligation to ensure the highest possible standard of health for citizens, the decentralized health system in Nigeria assigns primary responsibility for public health to subnational governments in the country (FGN, 1999). In the light of Nigeria's extremely high maternal mortality ratio, a human rights-based approach to improving maternal health would require that governments incorporate human rights standards into safe motherhood-related policies and practice (Yamin, 2008a; 2013b). This study evaluated the extent to which the Ondo State government incorporated human rights principles in the formulation and implementation of the Abiye safe motherhood initiative to meet the core needs of women of reproductive-age in relation to maternal health. Discussions are guided by the OHCHR human rights principles for understanding maternal mortality and morbidity as a rights issue. 
Principle of Accountability

Accountability is key to advancing health as a human right issue. Indeed it is "a cornerstone of the human rights framework, itself a system of norms that govern the relationship between "duty bearers" in authority and "rights holders" affected by their actions (Office of the United Nations High Commissioner for Human Rights (OHCHR), 2013). By means of accountability, individuals and communities are able to ensure that their governments (duty-bearers) oblige them the respect, protection and fulfilment of their rights (OHCHR, 2013). Right to life and protection of persons from indiscriminate and preventable loss of life, including preventable deaths related to pregnancy is the duty of government (Human Rights Committee, 1999). Accordingly, governments ought to create feedback structures that will facilitate the right to safe and dignified maternal health, as well as take responsibility for corrective action and remedies for women and families when violations are found (CRR, 2020; OHCHR, 2020). The findings of this study suggest that the Abiye safe motherhood initiative was enshrined on the human rights principle of accountability.

Prior the inception of the Governor Mimiko-led administration in 2009, Ondo State was a significant contributor to maternal deaths in Nigeria with a facility-based maternal mortality rate of 742 per 100,000 live births, which was worse than national average of 545 per 100,000 live births (NPC and ICF Macro, 2009). Consequently, the governor committed to ensure, in his words, "that pregnancy will no longer be a death sentence in the State". As a result, the Mother and Child Health initiative of the Ondo State government known as the Abiye (Safe Motherhood) initiative was established. In his words, the Governor of the State, Dr. Olusegun Mimiko said

... there is no question about the fact that when I came on board, I was able to lay it on the table where we were going, like I said we were concerned about health as a human right, ..., and we laid it on the table and I was able to communicate this vision to my cabinet and down the line, the vision cascaded and we found out that through the health system everyone was passionate about this.

Similarly, the Governor commented

The pregnant women of Ifedore have become real human beings to us.

They are flesh and blood now, not just statistics.

The Abiye initiative was created with accountability mechanisms that ensured that service providers provide quality service and service users could claim their rights to safe motherhood. For instance, incentives and sanctions are attached to deliveries outcomes, mobile phones with toll free lines that have access to relevant government authorities in situations of health service-related problem were distributed to pregnant women (Cooke and Tahir, 2013). A respondent confirmed the seriousness attached to maternal death audits in the state thus

... A law was established passed by the State House of Assembly that maternal death during labour or after delivery must be reported of which 
the government will take up the case... (Ondo State Ministry of Health Personnel)

\section{Principle of Participation}

According to the United Nations Population Fund (UNPF) (2005), "all people have the right to participate in and access information relating to the decision-making processes that affect their lives and well-being". The principle holds that individuals who are affected by a decision have a right to be involved in the decision-making process. Accordingly, all women have the right to be meaningfully involved in decision-making processes that bother on their right to safe and dignified maternal care, including decisions regarding government interventions and the way resources are distributed (CRR, 2020). This principle serves to empower women as active agents with rights to contribute to decisions that affect their sexual and reproductive health, as well as enable them to challenge every form of exclusion that prevents them from exercising their power to determine decisions and processes that affect their sexual and reproductive health. This principle of participation speaks to the need for meaningful involvement of beneficiaries in the policy process (OHCHR, 2020).

Stakeholder groups including women groups were involved in the conception and implementation of the Abiye Safe motherhood initiative. A government official stated

We decided to create awareness which started with engaging stake holders appropriately, what I mean is the traditional and religious governance structures- the Kabiyesis [kings], the Baales [chiefs], the Imams. Also, we engaged with other people who have strong influence in unions, market, cooperatives. Even tribal associations and political leaders were also carried along. There was like a town hall meeting especially at the pre-pilot stage where people were informed about the intention of the governor.

Following the consultations, the State organ actively disseminated agreements. An excerpt buttresses this point -

We had posters, we even had a CD that we distributed to pregnant women on the steps they need to take and all that. We did a lot on publicity on radio, on television but there were still some information gap at a stage but we did all we could to at least affect perception - Governor, Ondo state.

With the benefit of hindsight, the Governor commented

I would also have deepen community participation because ultimately, I started off with the assumption that it is people ownership that will sustain it but I have also found out that it takes time for people to own these things completely. Yes we involved the community but I would have deepened it and paid a lot of attention. I would have created a special advocacy department for it. I think those are the areas that I would have done things differently.

\section{Principle of Transparency}

Transparency is "built on the free flow of information" (UNDP policy, 1997). Transparency is about having access to government-held information which informs decisions on health care. 
Transparency is particularly crucial in matters of budgeting and funding allocations. It helps to build public confidence and trust about laws, policy and programmes of government. It strengthens the assurance that government efforts are for the good of society as a whole. In addition, the principle of transparency is critical for achieving other rights such as access to justice and freedom of speech. The government of Ondo State was unambiguous about its plans to tackle the maternal health crisis of the state at the time. Its communications via town halls and media, were important in helping the public understand its ideas and decisions and for building public support for Abiye program. According to the governor

We built in a robust health management information system. We collected data, we analyzed data and we used data, hardcore evidence as a basis for our policy and development along the way. (ODS_GOV)

We did a lot on publicity on radio, on television but there were still some information gap at a stage. (ODS_GOV)

The state's communication efforts served the purpose of updating the public on government's efforts regarding maternal mortality, helping the public understand the rationale behind policy changes, and the intended impact of changes on maternal health outcomes. According to a government respondent:

... being able to communicate in the language the community could understand, and getting the buy in of the people is one legacy that we left behind. (ODS_GOV)

Also, the principle of transparency in the realization of human rights can be applied to government's budget process. Over a seven-year period (2009 to 2016), Ondo State allocated an average of $5.75 \%$ of its total allocation to health; however, records or statistics on budget released are yet to be known.

\section{Principle of Empowerment}

Empowerment as a human right principle is about the entitlement of people with respect to certain aspects of their lives. Governments have an obligation to enable women to stay alive and make healthy choices in pregnancy and childbirth as part of their enjoyment of sexual and reproductive health rights (OHCHR, 2020). A human rights-based approach in relation to the health of women constitutes empowering women to claim their rights. Recognition of these rights to health includes enshrining sexual and reproductive health in constitutions and/or legislation, as well as putting in place mechanisms to redress any infringement on these health rights (OHCHR, 2020). This principle implies that "women and girls must be valued and engaged as agents and rights-holders when it comes to decisions or actions that affect their sexual and reproductive lives" (CRR, 2020).

Literature affirms that safe motherhood is a basic right (Fathalla, 2006) but a privilege in many low-and-middle-income countries (Maclean, 1996; Liljestrand, 2004; Fathalla, 2006). The Abiye Safe motherhood initiative, though conceived from the point of human right, is viewed by some as extending the privilege of a few to many. According to the United Nations, 
women have a right to safe motherhood; they have a right to be empowered to make choices that ensure their welfare and safety when they risk their life in order to give life.

With respect to the Abiye initiative, a service user confirmed that women were empowered.

Mimiko did well on health of women. They gave us pre-paid mobile phones to call rangers or ambulance service and anti-malaria bed nets. When there are problems, if you call the nearest facility, they will bring ambulance to pick you.

Furthermore, the intervention was scaled up to the other 17 local government areas of the State. As a result, four Basic Health Centres, two Comprehensive Health Centres and the General and Specialist Hospitals were designated as Abiye facilities totalling 116 facilities across the 18 local government areas of the State. In the implementation team of the Abiye initiative are the 'Abiye Rangers' and the 'Abiye Vanguards' responsible for coordinating home visits to the pregnant women and connecting them through their established structured referral mechanism, to skilled birth attendants (Cooke and Tahir, 2013).

\section{Principle of Sustainability}

Critical to a rights-based approach to maternal health is sustainability which emphasizes governments' obligation to dedicate the maximum accessible resources to sexual and reproductive health (OHCHR, 2020). Factors related to out-of-pocket costs, poor infrastructure, transportation, communication and language barriers, lack of cultural sensitivity and acceptance of traditional birthing customs, lack of respectful treatment, acceptability of care at facilities and overly restrictive laws, constitute threats to the human rights principle of sustainability and undermine the health system as a core social institution (OHCHR, 2020). Therefore, it is the duty of the state to make maternal health rights sustainable, through the allocation of "maximum available resources" (OHCHR, 2020) to progressively realize this goal as enshrined in the various international human rights mechanisms and resolutions, such as the Abuja Declaration, or the Committee on Economic, Social and Cultural Rights, which are expected to have been adopted into domestic law or Constitutional law (WHO, 2017).

Associated to the Abiye program is the Agbebiye initiative, a community-based approach and a PHC model aimed to further improve community ownership and sustainability. It is a performance-based approach that utilizes the carrot and stick principle to ensure compliance by the TBAs and MHBAs whom the government planned alternative means of livelihood for. A partnership was established between the government and the TBAs/MHBAs where they are expected to refer their pregnant clients to State health facilities where skilled birth attendants are available. Adherence was rewarded with a token of two thousand Naira per delivery of the pregnant woman in the health facility, as well as, offer of (TBAs/MHBAs) replacement job and an exit package of vocational skill acquisition (in soap and disinfectant making, hat and bead making, catering services and tie and dye making). Additionally, a microcredit soft loan of 100,000 Naira each, at no interest, was earmarked to establish new businesses for the TBAs/MHBAs (Ondo State Ministry of Health, 2017). 
Despite efforts by the Ondo State Government to make Abiye Safe motherhood initiative a home grown model of care for pregnant women, it seems to be hit by harsh economic realities that threatened its sustainability. A major limitation in the sustainability of the Abiye program was huge funds required for scale- up (Cooke and Tahir, 2013). In the effort to sustain the program, the state government applied for grants for the realization of improved health infrastructure and capacity in the two poorest local governments in the state, and intensified on internally generated revenue and international partnership (Cooke and Tahir, 2013). These efforts of government notwithstanding, the program began to wane as health service declined in quality and availability. This is confirmed below:

Things are no longer the same since I retuned here to have my second baby. I remember that when I had my first baby some years ago, I enjoyed fine treatment from the staff, beautiful environment and I was not asked to pay for anything. But now things are no longer as good. (Ondo State_ Service user).

...There is shortage of staff because of retirement and transfer cases with no replacement... (Ondo State Ministry of Health Personnel)

...there is lack of water supply. When I stayed here for four days, it was my husband that used kegs to fetch water for me. They said the pumping machine is spoilt. A place of delivery should have water for hygiene purposes. Babies are easily prone to diseases; they don't yet have much immunity. Apart from it, electricity supply is another problem. Although they put on generator and have solar light, but not always. There should be constant power supply. (Ondo State_ Service user)

There has not been regular power supply here in Igbokoda for years. There are times that the generating set breaks down during delivery. This is risky. There are no fans here too. This can lead to suffocation. (Ondo State_ Service user)

This is my first time at this general hospital. I don't like the idea of having to pay for hand gloves and drugs. Of what use is it a general hospital if we cannot get drugs for free. We pay for everything here. Once a woman is pregnant, it is difficult for her to work and earn money and yet we have to pay, the cost should be reduced. (Ondo State _ Service user)

Here in Igbokoda General Hospital, we pay every month for drugs; we also pay $\$ 50$ monthly for hand gloves just to get a tummy massage. This is not too good. Not everyone can afford to pay $\$ 50$ naira just for tummy massage. (Ondo State _ Service user)

...initially salary was regular but now not anymore, even until now the debt from Mimiko time is still on ground, staff are not paid. We work for four months we receive one month pay (Ondo State Ministry of Health Personnel)

...there is no question about the fact that when the recession set in, it affected our ability to pay the salary of civil servants generally, including 
health workers and of course that would dampen the enthusiasm of the health workers. (ODS_GOV)

\section{Principle of Non-discrimination}

The right to equality and non-discrimination enshrines that all persons be treated equally before the law, without discrimination, distinction or difference when equal cases are treated (Human Rights Committee, 1994; UDHR, 2005). In line with this principle overlapping forms of discrimination including maternal health violations, whether on the basis of gender, race or socioeconomic class should be effectively addressed (Human Rights Committee, 1994). Governments have a duty to ensure that socio-economic disparities do not shape or determine resource distribution in a way that systematically undermines disadvantaged women's right to life during pregnancy and childbirth. Typically, structural discrimination against women in the lower echelon of the socio-economic strata, manifests as "lower quality maternal health care services, disrespectful treatment, and ultimately, negative medical outcomes" (CRR, 2018). Therefore, a human rights-based approach to maternal health requires that governments ensure that the policies they create and their implementation, promote equality and non-discrimination that allows all women to claim their right to live the healthiest lives possible in pregnancy and childbirth (OUNHCHR, (2012).

The Abiye safe motherhood initiative was first pilot tested in Ifedore Local Government Area. The initiative was designed to provide equitable and non-discriminatory maternal health care services for women in rural and urban centres. By targeting disadvantaged women in marginalized communities (in riverine areas) and in the low-income echelon, the policy indisputably transformed the distribution of power and resources in the sector.

We developed a clear policy of maternal health on philosophical basis. I told you about access, we wanted people to have access, and we must break down financial barriers... (Ondo State Official)

Furthermore, the Abiye Safe motherhood programme provided services for people from other states without discrimination.

We have had to experience far too many patients than we can handle. We found out that many of them who come for services at Mother and Child are not residents of Ondo State (Ondo State _ Health Care Provider)

\section{Principle of International Assistance}

Collaborations to guarantee the right to health are growing and increasingly getting internationalized due to globalization (Pang and Guindon, 2004). In developing countries where there is particularly high burden of preventable conditions, the lack of resources or unwillingness of governments to ensure access to health-related services, puts citizens' right to health partly at the mercy of humanitarian and development assistance (Commission on Macroeconomics and Health, 2001, p.40). As an important part of development and poverty-reduction initiatives, developed countries in recent decades, have demonstrated growing commitment to responsibility of international assistance and cooperation to 
improving health in developing countries (Swedish International Development Cooperation Agency 2002, 7; U.K. Department for International Development 2007c, 3). Below is an example of international assistance acknowledged in relation to Abiye.

There is no question about the fact that World Bank and other multilateral agencies when they saw the delivery and the success we were recording, they were more interested about offering technical support, financial support (ODS_GOV).

We had support from multilateral agencies. We have WHO, we have all of these multilateral agencies, we have UNICEF and as a matter of fact, the B zone director of UNICEF before she left said look, I'm very excited about what I am seeing in Ondo state and I'm beginning to move one of my offices here and I think in 2015/16 they came and there is now a B zone office in Akure. When they opened the office, we had consultancy services free of charge (ODS_GOV).

Guaranteeing maternal health rights is not only germane considering that women deserve a right to health but also crucial seeing that virtually all maternal deaths are avoidable (Bustreo,et al, 2013). Adopting human rights principles as a basis for evaluating efforts of governments, communities and individuals towards safe motherhood is pertinent if there will be improvements in maternal mortality and morbidity that are guaranteed within safe and respectful maternal health care (Jolly, Aminu, Mgawadere, \& van den Broek, 2019). That Ondo State exemplified significantly improved maternal mortality rate in a short period is not apart from the state's efforts (Abiye) to address delays in health seeking, reaching care, accessing care and referring care which are typically experienced by disadvantaged women (Cooke and Tahir, 2013). The Abiye policy of Ondo state took into account structural inequities in maternal health care provision and focused on opening opportunities wherein the rights of pregnant women can be guaranteed and claimed. However, Abiye had lapses in transparency, accountability and sustainability of the policy.

\section{Conclusion}

The Abiye safe motherhood initiative exemplified human rights principles in addressing the sources and drivers of maternal mortality in Ondo State. The policy met the maternal health needs reproductive-age women in fairly acceptable and equitable ways; allowing the creation of opportunities and enabling conditions for the fulfillment of their rights. By targeting disadvantaged women in marginalized communities, the policy indisputably transformed the distribution of power and resources in the sector though with limited accountability and transparency and sustainability. Therefore, the starting point for governments in contributing to the prevention of maternal morbidity and mortality is recognizing that maternal mortality is a product of lapses in guaranteeing the human and reproductive rights of all women. Hence, governments at all levels should embrace and prioritize a human rights-based approach to maternal health where policies and programs meet the core needs of respect and welfare of every woman in pregnancy and childbirth. 


\section{Acknowledgments}

This research was supported by "Consortium for Advanced Research and Training in Africa (CARTA). CARTA is jointly led by the African Population and Health Research Center and the University of the Witwatersrand and funded by the Carnegie Corporation of New York (Grant No-B 8606.R02), Sida (Grant No: 107768/Z/15/Z). The DELTAS Africa initiative is an independent funding scheme of the African Academy of Sciences (AAS)'s Alliance for Accelerating Excellence in Science in Africa (AESA) and supported by the New Partnership for Africa's Development Planning and Coordinating Agency (NEPAD Agency) with funding from Wellcome Trust (UK) and the UK government".

\section{References}

Abegaz, S. T. (2019). A Human Rights-Based Approach to Maternal and Child Health in Ethiopia: Does it Matter to Promote Health Equities?. In Democracy and Human Rights. IntechOpen.

Bankole, A., Sedgh, G., Okonofua, F., Imarhiagbe, C., Hussain, R., \& Wulf, D. (2009). Barriers to safe motherhood in Nigeria. New York: Guttmacher Institute, 17.

Bayou, Y. T. (2014). Maternal health care seeking behaviour and preferences for places to give birth in Addis Ababa, Ethiopia (Doctoral dissertation).

Bustreo, F., Say, L., Koblinsky, M., Pullum, T. W., Temmerman, M., \& Pablos-Méndez, A. (2013). Ending preventable maternal deaths: the time is now. The Lancet Global Health, 1(4), e176-e177.

Carpenito-Moyet, L. J. (2008). Nursing Diagnosis: Application to Clinical Practice (12th ed.). Making Health Policy: Understanding Public Health, Philadelphia: JB Lippincott.

Centre for Reproductive Rights. (CRR) (2018). Advancing Maternal Health as a Human Rights Issue. In Alliance, B. M. M. Black Mamas Matter: Advancing the Human Right to Safe and Respectful Maternal Healthcare. New York: Centre for Reproductive Rights. Pp.8-17.

Fathalla, M. F. (2006). Human rights aspects of safe motherhood. Best Practice \& Research Clinical Obstetrics \& Gynaecology, 20(3), 409-419.

Federal Government of Nigeria (FGN) (1999). The Constitution of the Federal Republic of Nigeria (as Amended). Lagos: Federal Government Press.

Federal Ministry of Health Nigeria (2014). Accelerating Progress to Achive the Health MDGs in Nigeria: Harmonized Country Plan of Priority Intervention for 2014-2015. In Izugbara, C.O., Wekessah, F.M. and Adedini, S.A. (2016). Maternal Health in Nigeria: A Situation Update. African Population and Health Research Center (APHRC), Nairobi, Kenya.

Grundy, J. \& Annear, P. (2010). Health-seeking behaviour studies: a literature review of study design and methods with a focus on Cambodia. Health policy and health finance knowledge hub working paper series no, 7. 
Human Rights Committee (1994). General Comment 18: Non-Discrimination (37th Sess., 1989), in Compilation of General Comments and General Recommendations Adopted by Human Rights Treaty Bodies, at 27-28, paras. 6-12, U.N. Doc. HRI/GEN/1/Rev.1.

Human Rights Committee (1999). Gen. Comment No. 6, supra note 13, at 177, para. 5; Human Rights Committee, Gen. Comment No. 28, supra note 15, at 229, para. 10; see also Special Rapporteur on Violence against Women, Its Causes and Consequences, Rep. of the Special Rapporteur on Violence against Women, Its Causes and Consequences, Ms. Radhika Coomaraswamy, in Accordance with Commission on Human Rights Resolution 1997/44 Addendum - Policies and Practices that Impact Women's Reproductive Rights and Contribute to, Cause or Constitute Violence against Women, para. 66, U.N. Doc. E/CN.4/1999/68/Add.4 (Jan. 21, 1999) (noting "[g]overnment failure to take positive measures to ensure access to appropriate health-care services that enable women to safely deliver their infants as well as to safely abort unwanted pregnancies may constitute a violation of a woman's right to life...").

Human Rights Committee, General Comment No. 6: Right to Life (Art. 6) (16th Sess., 1982), in Compilation of General Comments and General Recommendations Adopted by Human Rights Treaty Bodies, at 176, para. 1, U.N. Doc. HRI/GEN/1/Rev.9 (Vol. I) (2008) [hereinafter Human Rights Committee, Gen. Comment No. 6].

Hunt, P., \& Bueno De Mesquita, J. (2007). Reducing maternal mortality: the contribution of the right to the highest attainable standard of health. University of Essex, European Union and the United Nations Population Fund (UNFPA). Retrieved at https://www.unfpa.org/sites/default/files/pub-pdf/reducing_mm.pdf.

Izugbara, C. O., Wekesah, F. M., \& Adedini, S. A. (2016). Maternal health in Nigeria: a situation update. Nairobi, Kenya: African Population and Health Research Center.

Jolly, Y., Aminu, M., Mgawadere, F., \& van den Broek, N. (2019). "We are the ones who should make the decision"-knowledge and understanding of the rights-based approach to maternity care among women and healthcare providers. BMC pregnancy and childbirth, $19(1), 1-8$.

Liljestrand, J. (2004). Maternal Survival- A Question of Women's Value. Lakartidningen, 101(6), 478.

Maclean, G. (1996). Safe motherhood: A Basic Right or a Privilege of a Few?. Modern midwife, 6(9), 10.

National Population Commission (NPC) [Nigeria] and ICF International (2014). Nigeria Demographic and Health Survey 2013. Abuja, Nigeria, and Rockville, Maryland, USA: NPC and ICF International.

National Population Commission (NPC) [Nigeria] and ICF Macro. (2009). Nigeria Demographic and Health Survey 2008. Abuja, Nigeria: National Population Commission and ICF Macro. 
Office of the United Nations High Commissioner for Human Rights (OHCHR) (2013). Who Will Be Accountable? Human Rights and the Post-2015 Development Agenda - Summary. Center for Economic and Social Rights (CESR) and the Office of the United Nations High Commissioner for Human Rights. Retrieved from Abridged_vers_WWBA_EN.indd (ohchr.org).

Office of the United Nations High Commissioner for Human Rights (OHCHR) (2020). Human Rights-Based Approach to Reduce Preventable Maternal Morbidity and Mortality: Technical Guidance. Retrieved from https://www.ohchr.org/Documents/Issues/Women/WRGS/Health/ TGReduceMaternalMortality.pdf (ohchr.org).

Office of the United Nations High Commissioner for Human Rights (OUNHCHR) (2012), Technical Guidance on the Application of Human Rights-Based Approach to Implementation of Policies and Programmes to Reduce Preventable Maternal Morbidity and Mortality, para. 85, U.N. Doc. A/HRC/21/22 (July 2, 2012). 30 ICPD Programme of Action, supra note 1, para. 14.3. 31 See ESCR Committee, Gen. Comment No. 14, supra note 9, para. 12.

Olonade, O., Olawande, T. I., Alabi, O. J., \& Imhonopi, D. (2019). Maternal Mortality and Maternal Health Care in Nigeria: Implications for Socio-Economic Development. Open Access Macedonian Journal of Medical Sciences, 7(5), 849.

Ondo State Ministry of Health. (2017). The Concept of Agbebiye Initiative as a Strategy for Maternal Death Reduction in Ondo State. Akure: Ondo State Government.

Panel, A. P. (2010). Maternal Health: investing in the Life Line of Healthy Societies \& Economies. Africa Progress Panel.

Pang, T., \& Guindon, E. (2004). Globalization and risks to health. EMBO Rep. 5(Suppl 1): S11-S16.

Piane, G. M. (2019). Maternal Mortality in Nigeria: A Literature Review. World Medical \& Health Policy, 11(1), 83-94.

Rosenfield, A., \& Maine, D. (1985). Maternal mortality-a neglected tragedy: Where is the M in MCH?. The Lancet, 326(8446), 83-85.

Rudan, I., Kapiriri, L., Tomlinson, M., Balliet, M., Cohen, B., \& Chopra, M. (2010). Evidence-based priority setting for health care and research: tools to support policy in maternal, neonatal, and child health in Africa. PLoS Med, 7(7), e1000308.

Shiffman, J., \& Okonofua, F. E. (2007). The state of political priority for safe motherhood in Nigeria. BJOG: An International Journal of Obstetrics \& Gynaecology, 114(2), 127-33.

Silverman, D. (2006). Interpreting Qualitative Data: Methods for Analysing Talk, Text, and Interaction. (3rd $\quad$ Ed.). Retrieved from https://www.amazon.com/Interpreting-Qualitative-Data-Analyzing-Interaction/dp/141292245 3. Accessed 04/02/2017. 


\section{Macrothink}

Journal of Public Administration and Governance ISSN 2161-7104 2020, Vol. 10, No. 4

Stanton, M. E., Kwast, B. E., Shaver, T., McCallon, B., \& Koblinsky, M. (2018). Beyond the Safe Motherhood Initiative: Accelerated action urgently needed to end preventable maternal mortality. Global Health: Science and Practice, 6(3), 408-412.

Storeng, K. T. (2010). Safe motherhood: The making of a global health initiative (Doctoral dissertation, London School of Hygiene \& Tropical Medicine).

Strauss, N., \& Ward, R. (2013). A human rights-based approach to maternal mortality in the United States. In Maternal Mortality, Human Rights and Accountability (pp. 94-112). Routledge.

Swedish International Development Cooperation Agency 2002, 7;

Ten Have, P. (2003). Understanding qualitative research and ethnomethodology. Sage.

U.K. Department for International Development 2007c, 3).

UNDP policy document (1997). Governance for Sustainable Human Development. New York: United Nations Development Programme; 1997:19.

United Nations Population Fund (UNPF) (2005). Human Rights Principles. Retrieved from https://www.unfpa.org/resources/human-rights-principles.

Universal Declaration of Human Rights (UDHR, 2005). UN Documentation: Human Rights. Retrieved from https://research.un.org/en/docs/humanrights.

WHO (2013). The Right to Health. Fact sheet N³23. Retrieved from http://www.who.int WHO (2019). Maternal deaths: Maternal Mortality Ratio (per 100000 live births). Retrieved from

https://www.who.int/data/gho/data/themes/topics/indicator-groups/indicator-group-details/G $\mathrm{HO} /$ maternal-deaths

World Health Organization (WHO) (2001). Commission on Macroeconomics and Health. Macroeconomics and health: Investing in Health for Economic Development. P.40. Geneva.WHO.

World Health Organization (WHO) (2017). Human Rights And Health. Retrieved from https://www.who.int/news-room/fact-sheets/detail/human-rights-and-health

Yamin, A. E. (2008). Beyond compassion: the central role of accountability in applying a human rights framework to health. Health and human rights, 1-20.

Yamin, A. E. (2008). Will we take suffering seriously? Reflections on what applying a human rights framework to health means and why we should care. Health and human rights, 45-63.

Yamin, A. E. (2013). From ideals to tools: applying human rights to maternal health. PLoS Med, 10(11), e1001546. 


\section{Macrothink}

Journal of Public Administration and Governance

ISSN 2161-7104 2020, Vol. 10, No. 4

Yamin, A. E. (2013). Applying human rights to maternal health: UN Technical Guidance on rights-based approaches. International Journal of Gynecology \& Obstetrics, 121(2), 190-193.

\section{Copyright Disclaimer}

Copyright for this article is retained by the author(s), with first publication rights granted to the journal.

This is an open-access article distributed under the terms and conditions of the Creative Commons Attribution license (http://creativecommons.org/licenses/by/4.0/). 